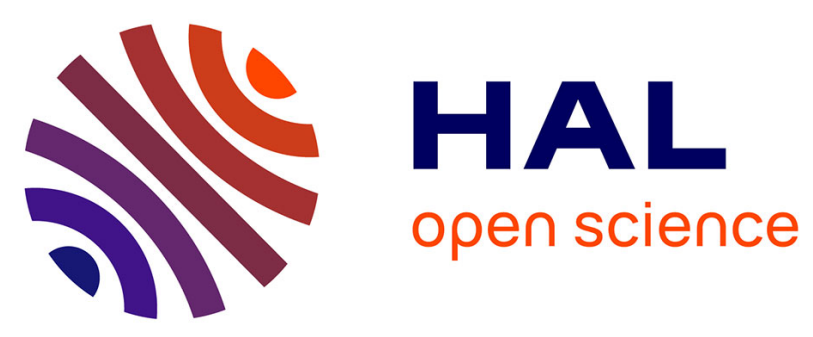

\title{
Short-term weight change and fluctuation as risk factors for type 2 diabetes in Finnish male smokers
}

\author{
Merja Kataja-Tuomola, Jari Sundell, Satu Männistö, Mikko J. Virtanen, \\ Jukka Kontto, Demetrius Albanes, Jarmo Virtamo
}

\section{To cite this version:}

Merja Kataja-Tuomola, Jari Sundell, Satu Männistö, Mikko J. Virtanen, Jukka Kontto, et al.. Shortterm weight change and fluctuation as risk factors for type 2 diabetes in Finnish male smokers. European Journal of Epidemiology, 2010, 25 (5), pp.333-339. 10.1007/s10654-010-9444-6 . hal00581004

\section{HAL Id: hal-00581004 https://hal.science/hal-00581004}

Submitted on 30 Mar 2011

HAL is a multi-disciplinary open access archive for the deposit and dissemination of scientific research documents, whether they are published or not. The documents may come from teaching and research institutions in France or abroad, or from public or private research centers.
L'archive ouverte pluridisciplinaire HAL, est destinée au dépôt et à la diffusion de documents scientifiques de niveau recherche, publiés ou non, émanant des établissements d'enseignement et de recherche français ou étrangers, des laboratoires publics ou privés. 
3Short-term Weight Change and Fluctuation as Risk Factors for Type 2 Diabetes 4in Finnish Male Smokers

5

6Merja Kataja-Tuomola ${ }^{1}$, Jari Sundell ${ }^{1}$, Satu Männistö ${ }^{1}$, Mikko J. Virtanen ${ }^{1}$, Jukka 7Kontto ${ }^{1}$, Demetrius Albanes ${ }^{2}$, Jarmo Virtamo $^{1}$

8

9WORD COUNT: abstract: 246

$10 \quad$ text: 2986

11NUMBER OF FIGURES: 2

12NUMBER OF TABLES: 2

13KEYWORDS: Cohort study; diabetes; weight change; weight fluctuation

14

15Conflict of interest: Merja Kataja-Tuomola ${ }^{1}$, Jari Sundell ${ }^{1}$, Satu Männistö ${ }^{1}$, Mikko 16J. Virtanen ${ }^{1}$, Jukka Kontto ${ }^{1}$, Demetrius Albanes ${ }^{2}$, Jarmo Virtamo' ${ }^{1}$, no conflicts of 17 interest.

18

19Affiliations of authors:

$20^{1}$ Chronic Disease Epidemiology and Prevention Unit

21 National Institute for Health and Welfare

22 Helsinki, Finland

$24^{2}$ National Cancer Institute, NIH

25 Bethesda, MD, USA

26Corresponding author: 
27Merja Kataja-Tuomola, MD

28Chronic Disease Epidemiology and Prevention Unit

29National Institute for Health and Welfare

30PL 30

3100271 Helsinki

32Finland

33

34Phone +358-206108739

$35 F a x+358-206108742$

36E-mail: merja.kataja-tuomola@thl.fi

37

38Abbreviations:

39ATBC Study Alpha-Tocopherol, Beta-Carotene Cancer Prevention Study

40BMI Body mass index

41HDL High density lipoprotein

42RR Relative risk

43RMSE Root mean square error

$4495 \%$ CI $\quad 95 \%$ Confidence interval

45

46 


\section{Abstract}

48Risk of weight change and fluctuation for type 2 diabetes was studied in a prospective 49study among 20,952 Finnish male smokers aged 50 to 69 years. Baseline data on 50lifestyle and medical history were collected, and height and weight measured. Weight 51was measured thrice after the baseline, one year apart. Weight change was defined as 52the slope of the regression line fitted to the four measurements and weight fluctuation 53as the root-mean-square-error deviation from this line. Incident cases of diabetes were 54identified from a national medication reimbursement register; 535 cases up to 9 years' 55 follow-up. The Cox proportional hazards model served to estimate relative risk (RR, $5695 \%$ confidence interval [CI]). Weight gain and fluctuation associated with higher 57risk for diabetes, multivariate $\mathrm{RR}=1.77,95 \% \mathrm{CI} 1.44-2.17$, for weight gain of at least $584 \mathrm{~kg}$ compared with those of weight change less than $4 \mathrm{~kg}$, and $\mathrm{RR}=1.64,95 \% \mathrm{CI}$ 591.24-2.17 in the highest weight fluctuation quintile compared to the lowest. These 60RRs remained similar when weight change and fluctuation were adjusted for each 61 other. Large weight fluctuation increased the risk of diabetes both in men who gained 62weight ( $\geq 4 \mathrm{~kg})$, had stable weight $( \pm<4 \mathrm{~kg})$, and lost weight $(\geq 4 \mathrm{~kg}) ; \mathrm{RR}=2.17,95 \%$ 63CI 1.60-2.94, $\mathrm{RR}=1.47,95 \% \mathrm{CI} 1.14-1.91$, and $\mathrm{RR}=2.04,95 \% \mathrm{CI} 1.47-2.83$, 64respectively, compared to those with stable weight and moderate fluctuation. Short65term weight gain and large weight fluctuation are independent risk factors for 66diabetes.

67

68

69 


\section{Introduction}

74Obesity, physical inactivity and smoking are established and modifiable risk factors 75 for type 2 diabetes [1-10]. The risk for developing type 2 diabetes also increases with 76age $[3,4,6]$. When dietary and lifestyle factors were analysed simultaneously in the 77Nurses' Health Study, the most important risk factor for type 2 diabetes was a higher 78body mass index (BMI, weight $(\mathrm{kg}) /$ height $\left.(\mathrm{m})^{2}\right)$ [11].

79Weight gain has been associated with the risk for type 2 diabetes [10, 12-15]. 80Weight loss can prevent or delay the progression to diabetes in obese patients $[16,17]$, 81though some studies have linked weight loss to increased risk for diabetes $[18,19]$. 82Unintentional weight regain frequently follows intentional weight loss, thus leading 83easily to weight cycling, which appears to enhance subsequent weight gain and may 84predispose one to obesity [20-23]. Findings concerning the association between 85 weight fluctuation or cycling and the risk for type 2 diabetes remain controversial; 86 three studies have found weight fluctuation to increase the risk for diabetes $[16,18$, 8724], but other three studies have found no significant association [23, 25, 26]. $88 \mathrm{We}$ studied the association of various weight change patterns, specified as weight 89gain, weight loss, and weight fluctuation, with the risk for type 2 diabetes in Finnish 90male smokers who participated in the Alpha-Tocopherol, Beta-Carotene Cancer 91Prevention Study (ATBC Study).

92

\section{Methods}

\section{The ATBC Study}

95The primary aim of the ATBC Study was to examine whether supplementation with 96alpha-tocopherol, beta-carotene, or both would reduce the incidence of lung cancer 
97and other cancers. The study was a randomized, double-blind, placebo-controlled 98 clinical trial with a $2 \times 2$ factorial design $[27,28]$. The participants were screened from 99among the total male population between the ages of 50 and 69 living in south100western Finland $(n=290,406)$. Men were excluded if they smoked fewer than 5 101 cigarettes per day, had prior cancer or a serious disease limiting long-term 102participation or used vitamin E, vitamin A or beta-carotene supplements in excess of 103predefined doses or anticoagulants. A total of 29,133 eligible men were enrolled from 1041985 through 1988, and the trial continued until April 1993 (median intervention 105time: 6.1 years), with the cohort followed up through national registers thereafter. The 106institutional review boards of the National Public Health Institute, Finland, and the 107U.S. National Cancer Institute approved the ATBC Study. All subjects provided their 108written, informed consent prior to randomization.

\section{Subjects and case ascertainment}

110In Finland, patients needing medical treatment for diabetes are entitled to 111 reimbursement for the cost of medication according to the sickness insurance 112legislation. This requires a medical certificate from the attending physician. The 113 certificate of every case is verified to fulfill the diagnostic criteria for diabetes at the 114Social Insurance Institution which maintains a central register of all patients receiving 115 drug reimbursement.

116This study included those men $(n=20,952)$ who had their weight measured at 117baseline and three times thereafter, one year apart after which the follow-up for 118diabetes began [Fig.1]. During a follow-up period of up to 9 years, 535 incident cases 119of diabetes were diagnosed. 


\section{Data collection}

121 At baseline, data on medical history, smoking, alcohol consumption and physical 122activity were collected with questionnaires. Height and weight were measured, and 123BMI was calculated. Blood pressure was measured with a mercury 124sphygmomanometer from the right arm with the subject sitting, and the lower reading 125of the two measurements taken at least one minute apart was recorded. A blood 126sample was drawn and serum stored at $-70^{\circ} \mathrm{C}$. Serum glucose was determined with the 127enzymatic hexokinase method using an Optima analyzer (ThermoFischer, Vantaa, 128Finland). Serum total and high-density lipoprotein (HDL) cholesterol concentrations 129 were determined enzymatically $[29,30]$.

130The participants made a follow-up visit three times annually, and weight was 131 measured once a year.

\section{Statistics}

133Person years were calculated from the date of the fourth annual weight measurement 134to the date of diabetes occurrence, death, or the end of the follow-up period 135(December 1997), whichever came first. The average trend in weight change was 136assessed through the slope of the regression line fitted to four weight measurements 137taken one year apart. The slope was categorized into three classes: below -1.33 $138(\mathrm{~kg} /$ year) for weight loss, between -1.33 and 1.33 for stable weight, and over 1.33 for 139weight gain. The $1.33 \mathrm{~kg} /$ year corresponded to an average weight change of $4 \mathrm{~kg}$ over 140three years. This was similar to a two-year net weight reduction of $2.7 \mathrm{~kg}$, which 141 associated with a 58\% reduction in diabetes risk in the Finnish Diabetes Prevention 142Study [31].

143To examine the association of risk for diabetes with weight fluctuation, we calculated 144the root mean square error (RMSE) using annual weight deviations from the 
145 corresponding estimated regression line $[18,32,33]$. This variable was divided into 146quintiles. Weight fluctuation and weight change were also considered as combined 147variable, in which case the weight fluctuation was categorized into two classes: Q1148Q4 for minor fluctuation and Q5 for large fluctuation.

149The association between weight indicators (short-term weight change and weight 150fluctuation) and the incidence of type 2 diabetes was estimated with the Cox 151 proportional hazards regression as relative risks (RR) and 95\% confidence intervals 152(CI). The basic model was adjusted for age and supplementation group. The model 153was further adjusted for BMI, years of smoking, number of cigarettes smoked daily, 154systolic and diastolic blood pressure, serum total and HDL cholesterol, alcohol 155consumption and leisure time physical activity (sedentary and moderate-heavy). 156Stratified analysis was performed in order to assess the possible effect modifications, 157 and the significance of interactions was tested using the likelihood ratio test. 158Differences between the groups were tested using analysis of variance (ANOVA). 159Analyses were carried out with the $\mathrm{R}$ statistical program [34]. All $p$ values were two160sided.

161

\section{Results}

163At baseline, men who gained on average at least $4 \mathrm{~kg}$ of weight during the subsequent 164three years, were slightly younger and had a lower serum total cholesterol 165 concentration than did those whose weight was stable or who lost at least $4 \mathrm{~kg}$ of 166weight (Table 1). Men whose weight fluctuated the most during the subsequent three 167years (fifth quintile) were younger and less physically active during leisure time, had 168a higher BMI, but lower serum total cholesterol and HDL cholesterol levels than did 169 men of the four lowest quintiles. 
170The multivariate-adjusted risk for diabetes was higher in men who gained at least $4 \mathrm{~kg}$ 171 during three years than in those whose weight was stable $(\mathrm{RR}=1.77,95 \% \mathrm{CI} 1.44-$ 1722.17) [Fig.2]. When compared to those with stable weight, weight loss of at least $4 \mathrm{~kg}$ 173 was not associated with the risk for diabetes $(\mathrm{RR}=1.17,95 \% \mathrm{CI} 0.90-1.53)$. Neither 174BMI, number of cigarettes, years of smoking, alcohol consumption nor physical 175activity modified the association between short-term weight change and the risk for 176diabetes. Age, however, did modify the risk for diabetes $(p=0.0067$ for weight gain 177 and $p=0.0036$ for weight loss). Among those 60 and older at baseline, weight gain as 178 well as weight loss were associated with higher risk for diabetes than among those of 179stable weight $(\mathrm{RR}=3.42,95 \%$ CI $1.70-6.88$, and $2.07,95 \%$ CI $1.08-3.99$, 180respectively), whereas among those younger than 60 , no association was observed $181(\mathrm{RR}=1.25,95 \% \mathrm{CI} 0.90-1.73$ and $\mathrm{RR}=0.74,95 \% \mathrm{CI} 0.55-1.01$, respectively $)$.

183 The risk for diabetes in the four lowest quintiles of weight fluctuation was similar, 184 whereas in the highest quintile the risk was higher than in the lowest quintile $(\mathrm{RR}=$ 1851.64, 95\% CI 1.24-2.17) [Fig.2]. Neither age, BMI, nor number of cigarettes 186significantly modified the association between short-term weight fluctuation and the 187risk for diabetes. Leisure time physical activity did modify the risk of diabetes with 188weight fluctuation $(p=0.02)$; among those of light leisure time physical activity, large 189 weight fluctuation was associated with increased risk for diabetes $(\mathrm{RR}=1.95,95 \% \mathrm{CI}$ 1901.28-2.98 for the highest vs. lowest quintile), whereas among those with moderate or 191heavy leisure time physical activity we found no such association $(\mathrm{RR}=1.38,95 \% \mathrm{CI}$ 1920.95-2.00). In addition, years of smoking modified the risk for diabetes $(p=0.04)$; 193among those who had smoked less than 36 years, large weight fluctuation increased 194the risk for diabetes $(\mathrm{RR}=1.91,95 \% \mathrm{CI} 1.27-2.88)$, whereas among those who had 
195 smoked at least 36 years, the association was weaker $(\mathrm{RR}=1.43,95 \%$ CI $0.98-2.09)$. 196Finally, the association of weight fluctuation to diabetes risk was stronger in men 197 who consumed on average $11 \mathrm{~g}$ or more of alcohol daily $(\mathrm{RR}=2.17,95 \% \mathrm{CI} 1.36$ 1983.45) than in men consuming less alcohol $(\mathrm{RR}=1.58,95 \% \mathrm{CI} 1.10-2.28 ; p=$ 1990.0001).

201Both short-term average weight change (slope) and weight fluctuation remained 202independent risk factors for diabetes when simultaneously adjusted for in the 203multivariate model: $\mathrm{RR}=1.69,95 \% \mathrm{CI} 1.37-2.07$, for a weight increase of at least 4 $204 \mathrm{~kg}$ compared with stable weight, and $\mathrm{RR}=1.55,95 \% \mathrm{CI} 1.17-2.06$, for the highest vs. 205lowest weight fluctuation quintile, respectively. Weight gain of at least $4 \mathrm{~kg}$ in three 206years, either steady or fluctuating, increased significantly the risk of diabetes about 207two-fold compared with those whose weight changed less than $4 \mathrm{~kg}$ and fluctuated 208only moderately (Table 2). Among men whose weight changed less than $4 \mathrm{~kg}$, large 209weight fluctuation increased the risk of diabetes 1.47 -fold, 95\% CI 1.14-1.91. Steady 210 loss of weight of at least $4 \mathrm{~kg}$ was associated non-significantly with decreased risk of 211diabetes, $\mathrm{RR}=0.73,95 \%$ CI $0.47-1.15$. However, if weight loss was associated with 212large weight fluctuation, the risk of diabetes was two-fold compared with those of 213stable weight and moderate fluctuation, $\mathrm{RR}=2.04,95 \%$ CI 1.47-2.83 (Table 2). 214

\section{Discussion}

216Short-term weight gain and fluctuation associated with a higher risk for diabetes. The 217 observation is in line with those of other epidemiological studies $[10,15]$. In the 218Health Professionals Follow-up Study, weight gain during the preceding ten years was 219associated with a 1.9 times higher risk for diabetes (95\% CI 1.4-2.7) among those 
220 who gained $9 \mathrm{~kg}$ or more of weight than among those with a stable weight $( \pm 2 \mathrm{~kg})$

221[15]. A parallel observation resulted in the National Health and Nutrition Examination 222Survey Epidemiologic Follow-up Study, where participants who gained weight at 223least $5 \mathrm{~kg}$ during 9 years had up to 3.85 times the risk for diabetes compared with 224participants whose weights remained relatively stable [10].

\section{5}

226An average weight loss of $4 \mathrm{~kg}$ in three years was not associated with a lower risk for 227incident diabetes. This differs from the findings of several prospective cohort and 228intervention studies where even modest weight loss was associated with a 229significantly reduced risk for diabetes [12, 31, 35-39]. In the Finnish Diabetes 230Prevention Study a net loss of $3.5 \pm 5.5 \mathrm{~kg}$ by the end of the second year decreased 231 risk of diabetes for $58 \%$ [31]. In the Nurse's Health Study women who lost more than $2325.0 \mathrm{~kg}$ reduced their risk for diabetes at least $50 \%$ compared to those who maintained 233a steady weight [12]. In the Diabetes Prevention Program (DPP) study, a $5 \mathrm{~kg}$ weight 234 loss accounted for a $55 \%$ reduction in risk of incident diabetes over the mean of 3.2 235years of follow-up [38]. Participants with intentional weight loss in the Cancer 236Prevention Study had a reduction of incident diabetes of about $25 \%$ compared with 237participants with no-intentional weight loss [39]. The unintentional weight loss may 238be an effect of diabetes per se, not a cause of diabetes.

239

$240 \mathrm{We}$ found that age did modify significantly the association between weight loss and 241risk of diabetes. Among men 60 years or older weight loss is associated with 242 increased risk, whereas among men younger than 60 years no such an association was 243evident. In the Iowa Women's Health Study of women aged 55-69 years and in a 
244Swedish study of middle-aged women, weight loss associated with increased risk of

245diabetes, but effect modification by age was not studied in these materials $[18,19]$.

246

247The association of weight loss in our study was, however, different depending on 248whether the weight decreased smoothly or fluctuating. If the weight diminished 249 smoothly, the risk of diabetes was decreased, though not significantly $(R R=0.73$, $25095 \%$ CI $0.47-1.15)$, which is in line with other studies. The small number of men with 251 smooth weight loss may be the reason why the decrease in risk remained non252significant. If the weight loss was associated with large weight fluctuation, it was 253associated with increased risk of diabetes.

254

255Our results support the hypothesis that weight fluctuation is associated with higher 256risk for diabetes. In the Iowa Women's Health Study, weight cycling (an increase of $257 \geq 10 \%$ of body weight during a ten-year period and a loss of $\geq 10 \%$ of weight during 258another ten-year period, regardless of order) increased significantly the risk for 259diabetes $(\mathrm{RR}=1.70,95 \% \mathrm{CI} 1.25-2.29)$ [18]. A similarly increased risk was found in 260an adult community where the adjusted rate ratio for diabetes risk was $1.7(p<0.01)$ 261 for the weight fluctuation (both weight gain and losses of $4.5 \mathrm{~kg}$ between ages 40 to 60 262vs. all others) [16]. In an other cohort study among women, an index of weight 263 fluctuation based on weights in different phases of life associated with diabetes with 264standardized odds ratio of 1.10 (95\% CI 1.07-1.14) [24]. Supportive evidence comes 265 from the Baltimore Longitudinal Study of Aging, where body weight variability 266associated with a decrease in glucose tolerance [32].

267Some studies, however, have found no association between weight fluctuation and the 268risk for diabetes. In a six-year follow-up of the Nurses' Health Study II, neither mild 
269nor severe weight cycling predicted diabetes [23]. In a prospective study among Pima 270Indians in Arizona, weight fluctuation was not associated with the incidence of 271diabetes in either sex [25]. In the Johns Hopkins Precursors Study the variability in 272BMI before age 50 predicted incident diabetes only marginally [26].

273

274Leisure time physical activity modified the association between weight fluctuation 275 and risk of diabetes. Large weight fluctuation increased the risk of diabetes two-fold if 276only light exercise were taken during leisure time whereas no association was found if 277 exercise was moderate or heavy. This is in keeping with the knowledge that physical 278activity can prevent diabetes. Regular exercise induces various adaptations in the 279 body resulting in improved muscle and whole body insulin sensitivity, fuel 280partitioning and cardiovascular function leading to prevention of metabolic disease $281[40,41]$.

282The strengths of our study include the prospective study design, with up to 9-year 283 follow-up for incident diabetes, and data available for several possible risk factors. 284Weight and height were measured by trained staff at study centres, not self-reported. 285The cases were retrieved from a nationwide register with strict criteria for inclusion. 286The trial supplementation had no effect on the incidence of diabetes [42]. 287Some limitations should be kept in mind, however, when interpreting these results. $288 \mathrm{We}$ were able to identify only patients receiving medication for treatment of diabetes, 289not individuals treating their disease with dietary changes. This will attenuate our 290estimate between weight indicators and risk of diabetes towards unity. The drug 291reimbursement register for diabetes contains no data on the type of diabetes. 292However, almost all of our diabetes cases would be of type 2 diabetes based on the 293age of the participants at baseline: 50 to 69 years [43]. Some [44, 45] but not all 
294studies [46] suggest that smoking cessation may associate with lower risk of diabetes. 295About $21 \%$ of the ATBC participants stopped smoking during the trial [28]. But we 296do not have smoking data from drop-outs and post-trial follow-up. Thus the possible 297effects of smoking cessation on our results remain unclear.

298For short-term weight change, we had only four weight measurements at intervals of 299 one year and were thus unable to detect weight variations occurring over a shorter 300period of time. No information on intentionality of weight changes was recorded. In 301addition, RMSE may have misclassified participants with continuous non-linear 302weight gain without real weight fluctuation [47].

303 The ATBC Study was designed to test whether alpha-tocopherol or beta-carotene 304 could reduce the incidence of lung or other cancers in male smokers, thus our results 305may not be generalizable to women or non-smokers.

306

307Globally, over one billion adults are overweight, of whom at least 300 million are 308obese [48]. If epidemic obesity increases worldwide, the disease burden of type 2 309diabetes and cardiovascular diseases will be enormous. Our results confirm that even 310a short-term weight gain is a risk factor for type 2 diabetes. They also contribute to 311 previous work by demonstrating a significant association between weight fluctuation 312and higher risk for diabetes. The association between weight fluctuation and risk for 313diabetes may raise concerns about health-promoting weight-control programs that 314 could result in such cycling. A key target could then be to maintain not only a normal, 315 but a stable body weight in order to optimally lower the risk for diabetes. 
318This ATBC Study was supported by U.S. Public Health Service contracts N01-CN31945165, N01-RC-45035, and N01-RC-37004 from the National Cancer Institute, NIH, 320and the Department of Health and Human Services.

321

322

323 
3261. Paffenbarger RS, Jr., Wing AL. Chronic disease in former college students.

327 XII. Early precursors of adult-onset diabetes mellitus. Am J Epidemiol. 1973;

$328 \quad 97: 314-23$.

3292. Modan M. Effect of past and concurrent body mass index on prevalence of

330 glucose intolerance and Type 2 (non-insulin-dependent) diabetes and on

331 insulin response. Diabetologia. 1986;29:82-9.

3323. Burchfiel CM, Curb JD, Rodriguez BL, Yano K, Hwang LJ, Fong KO, et al.

333 Incidence and predictors of diabetes in Japanese-American men. The Honolulu

334 Heart Program. Ann Epidemiol. 1995;5:33-43.

3354. Medalie JH, Papier CM, Goldbourt U, Herman JB. Major factors in the

336 development of diabetes mellitus in 10,000 men. Arch Intern Med. 1975;135:

$337 \quad 811-17$.

3385. Wilson PW, Anderson KM, Kannel WB. Epidemiology of diabetes mellitus in 339 the elderly. The Framingham Study. Am J Med. 1986;80:3-9.

3406. Feskens EJ, Kromhout D. Cardiovascular risk factors and the 25-year

341 incidence of diabetes mellitus in middle-aged men. The Zutphen Study. Am J

$342 \quad$ Epidemiol. 1989;130:1101-8.

3437. Ohlson LO, Larsson B, Björntorp P, Eriksson H, Svärdsudd K, Welin L, et al.

344 Risk factors for type 2 (non-insulin-dependent) diabetes mellitus. Thirteen and 345 one-half years of follow-up of the participants in a study of Swedish men born 346 in 1913. Diabetologia. 1988;31:798-805. 
3478. Helmrich SP, Ragland DR, Leung RW, Paffenbarger RS, Jr. Physical activity

348 and reduced occurrence of non-insulin-dependent diabetes mellitus. N Engl J

$349 \quad$ Med. 1991;325:147-52.

3509. Manson JE, Nathan DM, Krolewski AS, Stampfer MJ, Willett WC,

351 Hennekens $\mathrm{CH}$ A prospective study of exercise and incidence of diabetes

352 among US male physicians. JAMA. 1992;268:63-7.

35310. Ford ES, Williamson DF, Liu S. Weight change and diabetes incidence:

354 findings from a national cohort of US adults. Am J Epidemiol. 1997;146:214-

35522.

35611. Hu FB, Manson JE, Stampfer MJ, Colditz G, Liu S, Solomon CG, et al. Diet, 357 lifestyle, and the risk of type 2 diabetes mellitus in women. N Engl J Med. $358 \quad 2001 ; 345: 790-97$.

35912. Colditz GA, Willett WC, Rotnitzky A, Manson JE. Weight gain as a risk 360 factor for clinical diabetes mellitus in women. Ann Intern Med. 1995;122: $361 \quad 481-6$.

36213. Schienkiewitz A, Schulze MB, Hoffmann K, Kroke A, Boeing H. Body mass 363 index history and risk of type 2 diabetes: results from the European

364 Prospective Investigation into Cancer and Nutrition (EPIC)-Potsdam Study.

365 Am J Clin Nutr. 2006;84:427-33.

36614. Oguma Y, Sesso HD, Paffenbarger RS, Jr., Lee IM. Weight change and risk of 367 developing type 2 diabetes. Obes Res. 2005; 13:945-51.

36815. Koh-Banerjee P, Wang Y, Hu FB, Spiegelman D, Willett WC, Rimm EB.

369 Changes in body weight and body fat distribution as risk factors for clinical 370 diabetes in US men. Am J Epidemiol. 2004;159:1150-9. 
37116. Holbrook TL, Barrett-Connor E, Wingard DL. The association of lifetime

372 weight and weight control patterns with diabetes among men and women in an

373 adult community. Int J Obes. 1989;13:723-9.

37417. Pi-Sunyer FX. How effective are lifestyle changes in the prevention of type 2

375 diabetes mellitus? Nutr Rev. 2007;65:101-10.

37618. French SA, Folsom AR, Jeffery RW, Zheng W, Mink PJ, Baxter JE. Weight

377 variability and incident disease in older women: the Iowa Women's Health

378 Study. Int J Obes Relat Metab Disord. 1997;21:217-23.

37919. Noppa H. Body weight change in relation to incidence of ischemic heart

380 disease and change in risk factors for ischemic heart disease. Am J Epidemiol.

$381 \quad 1980 ; 111: 693-704$.

38220. Blackburn GL, Wilson GT, Kanders BS, Stein LJ, Lavin PT, Adler J, et al.

383 Weight cycling: the experience of human dieters. Am J Clin Nutr. 1989; 49

$384 \quad$ (Suppl):1105-9.

38521. Saarni SE, Rissanen A, Sarna S, Koskenvuo M, Kaprio J. Weight cycling of

386 athletes and subsequent weight gain in middleage. Int J Obes. 2006;30:1639-

$387 \quad 44$.

38822. Kroke A, Liese AD, Schulz M, Bergmann MM, Klipstein-Grobusch K,

389 Hoffmann K, et al. Recent weight changes and weight cycling as predictors of

390 subsequent two year weight change in a middle-aged cohort. Int J Obes Relat

391 Metab Disord. 2002;26:403-9.

39223. Field AE, Manson JE, Laird N, Williamsson DF, Willett WC, Colditz GA.

393 Weight cycling and the risk of developing type 2 diabetes among adult women

394 in the United States. Obes Res. 2004;12:267-74. 
39524. Morris RD, Rimm AA. Long-term weight fluctuation and non-insulin-

396 dependent diabetes mellitus in white women. Ann Epidemiol. 1992;2:657-64.

39725. Hanson RL, Narayan KM, McCance DR, Pettitt DJ, Jacobsson LT, Bennett

398 PH, et al. Rate of weight gain, weight fluctuation, and incidence of NIDDM.

399 Diabetes. 1995;44:261-6.

40026. Brancati FL, Wang NY, Mead LA, Liang KY, Klag MJ. Body weight patterns 401 from 20 to 49 years of age and subsequent risk for diabetes mellitus: the Johns 402 Hopkins Precursors Study. Arch Intern Med. 1999;159:957-63.

40327. The ATBC Cancer Prevention Study Group. The Alpha-Tocopherol, Beta-

404 Carotene Lung Cancer Prevention Study: design, methods, participant

$405 \quad$ characteristics and compliance. Ann Epidemiol. 1994;4:1-10.

40628. The ATBC Cancer Prevention Study Group. The effect of vitamin E and beta407 carotene on the incidence of lung cancer and other cancers in male smokers. $\mathrm{N}$ $408 \quad$ Engl J Med. 1994;330:1029-35.

40929. Kattermann R, Jaworek D, Möller G, Assmann G, Björkhem I, Svensson L, et 410 al. Multicentre study of a new enzymatic method of cholesterol determination. $411 \quad J$ Clin Chem Clin Biochem. 1984;22:245-51.

41230. Kostner G. Enzymatic determination of cholesterol in high density lipoprotein 413 fractions prepared by polyanion precipitation. Clin Chem. 1976;22:695.

41431. Tuomilehto J, Lindström J, Eriksson JG, Valle TT, Hämäläinen H, Ilanne415 Parikka P, et al. Prevention of type 2 diabetes mellitus by changes in lifestyle 416 among subjects with impaired glucose tolerance. N Engl J Med. 2001;344: $417 \quad 1343-50$.

41832. Lissner L, Andres R, Muller DC, Shimokata H. Body weight variability in 419 men: metabolic rate, health and longevity. Int J Obes. 1990;14:373-83. 
42033. Iribarren C, Sharp DS, Burchfiel CM, Petrovitch H. Association of weight loss 421 and weight fluctuation with mortality among Japanese American men. N Engl $422 \quad$ J Med. 1995;333:686-92.

42334. Ihaka R, Gentleman R. A language for data analysis and graphics. J Comput $424 \quad$ Graph Stat. 1996;5:299-314.

42535. Wannamethee SG, Shaper AG, Walker M. Overweight and obesity and weight 426 change in middle aged men: impact on cardiovascular disease and diabetes. J

$427 \quad$ Epidemiol Community Health. 2005;59:134-39.

42836. Resnick HE, Valsania P, Halter JB, Lin X. Relation of weight gain and weight 429 loss on subsequent diabetes risk in overweight adults. J Epidemiol Community $430 \quad$ Health. 2000;54:596-602.

43137. Davey Smith G, Bracha Y, Svendsen KH, Neaton JD, Haffner SM, Kuller LH. 432 Incidence of type 2 diabetes in the randomized multiple risk factor 433 intervention trial. Ann Intern Med. 2005;142:313-22.

43438. Hamman RF, Wing RR, Edelstein SL, Lachin JM, Bray GA, Delahanty L, et 435 al. Effect of weight loss with lifestyle intervention on risk of diabetes.

436 Diabetes Care. 2006;29:2102-7.

43739. Will JC, Williamson DF, Ford ES, Calle EE, Thun MJ. Intentional weight loss 438 and 13-year diabetes incidence in overweight adults. Am J Public Health. $439 \quad 2002 ; 92: 1245-8$.

44040. Christ-Roberts CY, Pratipanawatr T, Pratipanawatr W, Berria R, Belfort R, $441 \quad$ Kashyap S, et al. Exercise training increases glycogen synthase activity and 442 GLUT4 expression but not insulin signaling in overweight nondiabetic and 443 type 2 diabetic subjects. Metabolism. 2004;53:1233-42.

44441. Perseghin G, Price TB, Petersen KF, Roden M, Cline GW, Gerow K, et al. 
445 Increased glucose transport-phosphorylation and muscle glycogen synthesis

446 after exercise training in insulin-resistant subjects. $\boldsymbol{N}$ Engl J Med. 1996;335:

$447 \quad 1357-62$.

448 42. Kataja-Tuomola M, Sundell JR, Männistö S, Virtanen MJ, Kontto J, Albanes

449 D, et al. Effect of alpha-tocopherol and beta-carotene supplementation on the

450 incidence of type 2 diabetes. Diabetologia. 2008;51:47-53.

45143. Laakso M, Pyörälä K. Age of onset and type of diabetes. Diabetes Care. 1985;

$452 \quad 8: 114-7$

45344. Manson JE, Ajani UA, Liu S, Nathan DM, Hennekens CH. A prospective 454

45945. Will JC, Galuska DA, Ford ES, Mokdad A, Calle EE. Cigarette smoking and 460

46546. Beziaud F, Halimi JM, Lecomte P, Vol S, Tichet J. Cigarette smoking and 466 diabetes mellitus. Diabetes Metab. 2004;30:161-6.

468

46947. Vergnaud A-C, Bertrais S, Oppert J-M, Maillard-Teyssier L, Galan P, 470 Hercberg S, et al. Weight fluctuations and risk for metabolic syndrome in an $471 \quad$ adult cohort. Int J Obesity. 2008;32:315-21.

47248. World Health Organization. Obesity and overweight Geneva: WHO, 2004

473 Available:

474 http://www.who.int/dietphysicalactivity/publications/facts/obesity/en/ 
478Title to Figure 1.

479

480Figure 1. Diagram of flow of participants through the study

481

482

483

484

485 
29,133 randomized in the ATBC Study

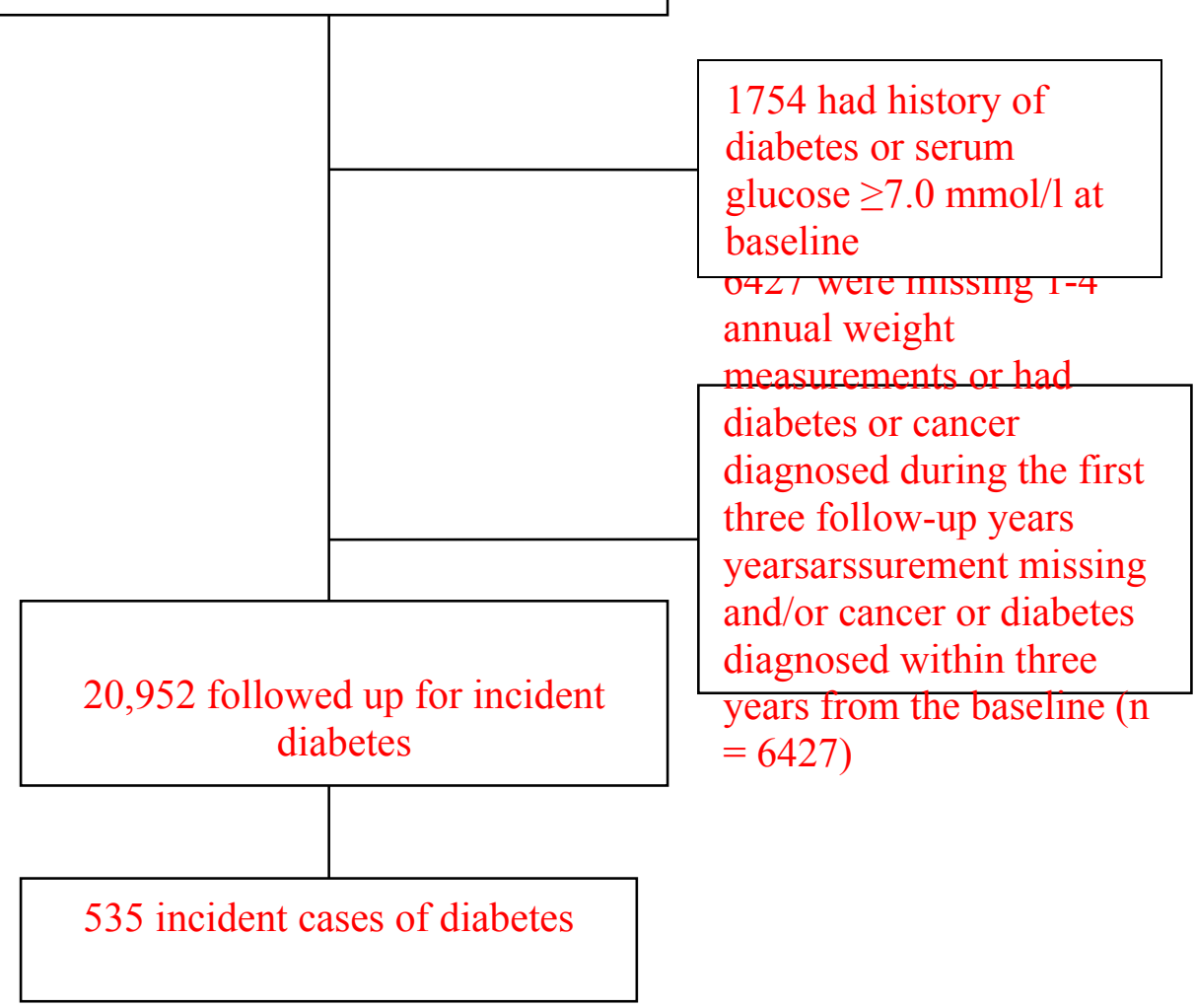


487Title to Figure 2

488Figure 2. Relative risk and 95\% confidence interval for diabetes by average weight change and weight fluctuation (RMSE) during 489three subsequent years in the ATBC Cancer Prevention Study cohort.

490

491Footnote to Figure 2

492Adjusted for age, intervention (alpha-tocopherol, beta-carotene, both, and placebo), body mass index, smoking, blood pressure, serum total and 493high density lipoprotein cholesterol, alcohol consumption and leisure time physical activity.

494The root mean square error (RMSE) is calculated using annual weight deviations from the corresponding estimated regression line and this 495variable is divided into quintiles (Q). Q1: -0.54, Q2: 0.55-0.84, Q3: 0.85-1.17, Q4: 1.18-1.67, Q5: 1.68.

496

497

498

499

500

501

502

503 
508Title to Table 1.

509Table 1 Trial baseline characteristics by weight changes during the subsequent three years in the ATBC Cancer Prevention Study

510cohort

511

512

513

514

515

516

517

518

519 


\begin{tabular}{|c|c|c|c|c|c|c|c|c|}
\hline 522Characteristic ${ }^{a}$ & Averag & weight chans & $\mathrm{e}^{\mathrm{b}}(\mathrm{kg})$ & & uintile of & ight fluct & $\operatorname{ion}^{\mathrm{c}}(\mathrm{kg})$ & \\
\hline $\begin{array}{r}523 \\
524\end{array}$ & Loss $(\geq 4)$ & Stable $( \pm<4)$ & Gain $(\geq 4)$ & -0.54 & $0.55-0.84$ & $0.85-1.17$ & $1.18-1.67$ & $1.68-$ \\
\hline 525 & & & & & & & & \\
\hline $527^{\mathrm{n}}$ & 2,108 & 15,347 & 3,497 & 4,248 & 4,244 & 4,224 & 4,163 & 4,073 \\
\hline Age, y & 57.6 & 56.9 & 56.2 & 57.1 & 56.9 & 57.2 & 56.8 & 56.4 \\
\hline Weight, kg & 82.5 & 77.1 & 79.5 & 75.6 & 76.5 & 76.9 & 78.9 & 82.8 \\
\hline BMI, $\mathrm{kg} / \mathrm{m}^{2}$ & 27.1 & 25.6 & 26.2 & 25.3 & 25.5 & 25.6 & 26.0 & 27.1 \\
\hline Number of cigarettes/day & 20 & 20 & 20 & 20 & 20 & 20 & 20 & 20 \\
\hline Smoking years & 37 & 36 & 35 & 36 & 36 & 36 & 36 & 35 \\
\hline Systolic blood pressure, $\mathrm{mmHg}$ & 142 & 140 & 140 & 140 & 140 & 140 & 140 & 140 \\
\hline Diastolic blood pressure, $\mathrm{mmHg}$ & 90 & 88 & 88 & 86 & 88 & 86 & 88 & 88 \\
\hline Serum cholesterol, mmol/l & 6.30 & 6.20 & 6.08 & 6.21 & 6.20 & 6.20 & 6.18 & 6.16 \\
\hline Serum HDL cholesterol, mmol/1 & 1.11 & 1.16 & 1.16 & 1.17 & 1.17 & 1.16 & 1.15 & 1.11 \\
\hline Alcohol consumption, g/day & 11 & 11 & 11 & 10 & 11 & 11 & 11 & 11 \\
\hline $\begin{array}{l}\text { Leisure time physical activity, } \\
\text { moderate or heavy, \% }\end{array}$ & 55 & 62 & 57 & 62 & 63 & 62 & 59 & 56 \\
\hline
\end{tabular}


528Footnote to Table 1

$529^{\text {a }}$ Medians or proportions

$530{ }^{\mathrm{b}}$ Weight change is based on the slope of the regression line fitted to the four weight measurements taken one year apart

$531^{\mathrm{c}}$ Weight fluctuation is the RMSE around the slope 
534Title to table 2

535

536Table 2. Risk for diabetes by weight change and weight

537

538 fluctuation in three years, in the Alpha-Tocopherol, Beta-Carotene

539

540(ATBC) Cancer Prevention Study cohort.

541

542

543

544

545

546

547

548

549

550

551

552

553

554

555

556

557

558

559

560

561

562

563

564

565 
568 569 Weight change Weight fluctuation

570 Stable (quintiles $1-4^{\mathrm{a}}$ )

Large (quintile $5^{\mathrm{a}}$ )

571 cases person years $\mathrm{RR} \quad 95 \% \mathrm{CI}$ cases person years $\mathrm{RR} \quad 95 \% \mathrm{CI}$

572 
587Footnote to table 2 .

588

589Adjusted for baseline age, intervention (alpha-tocopherol, beta-carotene, both and 590

591placebo), BMI, smoking, blood pressure, serum total and HDL cholesterol, alcohol 592

593consumption and leisure time physical activity

$594^{\mathrm{a}}$ The total number of participants is 20,952 divided in quintiles. 